\title{
Physical Properties of Dates Fruits
}

\author{
N.N. Desai ${ }^{1}$, V.M. Modi ${ }^{1}$, G.K. Saxena ${ }^{2}$, Ramesh Harajibhai Chaudhari ${ }^{1}$, \\ Manoj Kumar Jaipal ${ }^{3}$, K.H. Gohil ${ }^{1}$ and Alok Gora ${ }^{2^{*}}$ \\ ${ }^{1}$ College of Renewable Energy and Environmental Engineering \\ ${ }^{2}$ Department of Agricultural Engineering, C.P. College of Agriculture \\ ${ }^{3}$ College of Food Technology, Sardarkrushinagar Dantiwada Agricultural University, \\ Sardarkrushinagar- 385506 (Gujarat), India \\ *Corresponding author
}

\section{Keywords}

Date palm,

Physical Properties

Phoenix

dactylifera

Article Info

Accepted:

10 March 2019

Available Online:

10 April 2019

\section{A B S T R A C T}

Date palm (Phoenix dactylifera L.) is a monocotyledon of the family of the Palmae. The date palm is grown in Kutchh region of Gujarat. The physical properties of dates fruits (Variety: Zahidi) are necessary for the design of the equipment to handle, transport, process and storage. In this study some physical properties of dates fruits determined as a function of moisture content namely, dimensions, arithmetic and geometric mean diameter, sphericity, surface area, 1000 unit mass, bulk density, true density, porosity, angle of repose and coefficient of static friction. The average values of length, breadth and thickness of date palm fruit at different moisture content 69.5 and $61.56 \%$ (w.b.) were found to be 33.65 and $33.12 \mathrm{~mm}, 22.12$ and $22.03 \mathrm{~mm}, 20.02$ and $19.95 \mathrm{~mm}$ respectively. The arithmetic and geometric mean diameter of fresh date fruit ranged from 24.29-26.59 $\mathrm{mm}$ and 23.51-25.96 $\mathrm{mm}$ respectively. The value of sphericity for different moisture content varied from 0.73 to 0.737 . The bulk density varied from 491 to $477 \mathrm{~kg} / \mathrm{m}^{3}$. The true density decreased from 576 to $533 \mathrm{~kg} / \mathrm{m}^{3}$. The porosity varied from 10.56 to $14.75 \%$ for the moisture content of 61.56 and $69.5 \%$ (w.b.). The angle of repose increased from 18.76 to $21.34^{\circ}$. It was found that the coefficient of static friction of date fruits varied from 0.31-0.35 (wood surface), 0.30-0.33 (steel surface) and 0.25-0.27 (glass surface).

\section{Introduction}

Date palms are the fruits grow on the palm tree belonging to the family of Arecaceae in the genus: Phoenix and scientifically named as Phoenix dactylifera. Kutch is the largest Date-palm producing region in India, with a whopping total area under Date-palm farming of 16,000 hectare and production of 1.2 lakh tonnes, Pakistan and India hold a significant position in international Dates market, former as a second largest exporter and later being the largest importer of dates in the western border of India and the coastal belt of Kutch district of Gujarat contributes about ninety percent to the total date production in India. More than 1.5 million date palm trees are present in Kutch, spread widely from Anjar to 
Mandvi including Mundra and other areas. This seed propagated population represents a huge biodiversity of date palm with fruits of varying qualities. Government initiatives to promote date palm culture especially in Gujarat and Rajasthan states leads to significant increase in area and production of date palm during the last 15 years. In Kutch, for example, the area under cultivation increases from 8,973 ha to 16,000 ha during last ten years. Date Palm Research Centres at Mundra in Kutch, Bikaner and Jodhpur in Rajasthan, Hissar in Haryana and Abohar in Punjab are working for the promotion of date palm in their respective regions. There is a need for a comprehensive study of the physical properties of date to develop appropriate technologies for its processing. The development of the technologies will require the properties of this fruit. It becomes imperative to characterize the fruits with a view to understand the properties that may affect the design of machines to handle their processing. Date (Phoenix dactylifera) is well known for its nutritional contents. It contains $1.9 \%$ protein, $70.6 \%$ carbohydrates, $2.5 \%$ fat, $1.2 \%$ minerals and $10 \%$ fiber 1 . The dates are considered as prime fruit for their nutritional and therapeutic value.

\section{Materials and Methods}

\section{Physical properties of date fruits}

Fresh dates which was harvested in the month of June of variety Zahidi was used as a raw material for drying study. About $500 \mathrm{~kg}$ fresh date of variety zahidi was procured from main date palm Research Station, S.D. Agricultural University, Mundra (Kutchh).

Five samples having $100 \mathrm{~g}$ weight were drawn randomly and initial moisture content of fresh date was determined. The dates were cleaned and washed. The date were sorting by manually to remove foreign matters, leaves and immature dates. The physical properties of fresh date fruits such as size in terms of length, breadth and thickness, arithmetic mean diameter, geometric mead diameter, sphericity, bulk density, true density, porosity, angle of repose and coefficient of static friction were determined The methods employed are referred below. Ten replications were made for each sample and average value has been reported.

\section{Measurement of size}

A sample of randomly selected hundred fruits was used to determine the average size of date fruit at each moisture content level. Mass of individual fruit were determined using an electronic balance with a sensitivity of $0.01 \mathrm{~g}$. Fruit volume will be measure by water displacement method. The principal dimensions of date fruits in terms of length, breadth and thickness are measured with help of vernier calipers (Mitu and Toyo, Japan) reading to $0.01 \mathrm{~mm}$. The longest dimensions in the longitudinal direction were considered as length. The triaxial dimensions are measured for 100 fruits randomly selected from the bulk of date fruits. The average value of 100 observations is reported.

\section{Arithmatic and geometric mean diameter}

For determination of arithmetic and geometric mean diameter of dates fruit, values of length, width and thickness were used. Arithmatic and geometric mean diameter of date fruits was calculated by using the following relationship (Mohsenin, 1980). The arithmetic and geometric mean diameter is important in role processing in general.

\section{Sphericity}

For determination of sphericity of date fruit is considered to be a triaxial ellipsoid with length, width and thickness as intercepts 
respectively. Sphericity of date fruit was calculated using following formula (Mohsenin, 1980).

Sphericity $(\varnothing)=(\mathrm{abc})^{1 / 3} / \mathrm{a}$

\section{Surface area}

The surface area of date fruit was determined by analogy with a sphere of the some geometric mean diameter using the following equation.

$\mathrm{S}_{\mathrm{a}}=\pi \mathrm{D}_{\mathrm{g}}^{2}$

\section{One thousand fruit mass}

To evaluate the 1000 fruit mass, 10 randomly selected fruits from each moisture level are weighed on a digital electronic balance $(\mathrm{K}$ Roy Electronics) having an accuracy of 0.001 g.

\section{Bulk density $\left(\rho_{\mathrm{b}}\right)$}

Bulk density as the ratio of weight of fruits to the volume occupied by the same fruits was measured with help of two cylinders having volume of 1000 and $1500 \mathrm{ml}^{-}$The bulk density was expressed in $\mathrm{kg} / \mathrm{m}^{3}$.The bulk density of the fruits was determined as follow.

$\rho_{b}=\mathrm{M} / \mathrm{V}$

\section{True density $\left(\rho_{t}\right)$}

The true density as a function of water content was determined using the toluene displacement method in order to avoid absorption of water during experiment. Toluene was used instead of water because it is less absorbed by fruits, its surface tension is low so that it fills even shallow dips in fruits, its dissolution number is low (Mohsenin,1980). The fruits were used to displace toluene in a measuring cylinder after their masses have been measured. The true density was found as an average of the ratio of their masses to the volume of toluene displaced by the fruit.

\section{Porosity}

The porosity is the fraction of the space in the bulk fruits which is not occupied by the fruits. The porosity of bulk fruit was calculated from the values of true density and bulk density using the relationship given by Mohsenin (1980) as follow.

$£, \%=\left(1-\rho_{\mathrm{b}} / \rho_{\mathrm{t}}\right) \times 100$

\section{Angle of repose}

The angle of repose is the characteristic of the bulk material which indicates the cohesion among the individual fruits. If higher cohesion between fruits then the high value of angle of repose obtained. The angle of repose is the angle from the horizontal at which the material will rest in a pile (Pradhan et al., 2009). The angle of repose of date palm was determined by standard circular platform method. The box having circular platform fitted inside was fitted with fruit. The extra fruit surrounded the platform was remove through discharge hole leaving a free standing cone of fruits on the circular platform. A stainless steel scale was use to measure the height of the cone and angle of repose was calculated by this formula.

$\mathrm{Q}=\operatorname{Tan}^{-1}(2 \mathrm{~h}) / \mathrm{d}$

\section{Coefficient of static friction}

The experiment for determination of static coefficient of friction was performed of date fruit using test surfaces against wood, steel and glass surfaces with five replications. Experiment was performed on a tilting platform of $350 \mathrm{~mm} \mathrm{X} 120 \mathrm{~mm}$. An open 
ended plastic cylinder having $65 \mathrm{~mm}$ diameter $40 \mathrm{~mm}$ height was filled with the fruit and placed on the adjustable tilting surface. The platform was raised slightly so as not to touch the table surface.

The platform was inclined gradually with a screw device until the cylinder just started to slide down. The tangent of angle was taken as coefficient of static friction between the surface and date fruits given by $\mu$ as under.

$\mu=\tan \phi$

\section{Results and Discussion}

\section{Dimensions of date palm fruits}

The dimensions are important physical parameters for drying and storage studies of date palm fruits. Apart from that, the dimensions could be useful for determining the shape of the fruits. The average dimensions of date palm fruits at different moisture contents are presented in Table 1.

The mean value of three axial dimensions i.e. length, breadth and thickness of 100 fruits measured at moisture contents of 69.5 percent and 61.56 percent (w.b.) were $33.65 \mathrm{~mm}$ and $33.12 \mathrm{~mm}, 22.12 \mathrm{~mm}$ and $22.03 \mathrm{~mm}$ and $20.02 \mathrm{~mm}$ and $19.95 \mathrm{~mm}$ respectively. It was found that the value of breadth and thickness were very close to each other.

Jahromi (2007) studied the that, linear dimensions varied from 33.10 to $42.60 \mathrm{~mm}$ in length, 18.20 to $25.30 \mathrm{~mm}$ in width and 17.40 to $24.40 \mathrm{~mm}$ in thickness. The relationships between the axial dimensions (length, breadth and thickness) and moisture content can be expressed using the regression equation as:

$$
\begin{aligned}
& \mathrm{L}=0.79 \mathrm{M}+6.425, \mathrm{R}^{2}=0.3156 \\
& \mathrm{~B}=0.8343 \mathrm{M}+3.74, \mathrm{R}^{2}=0.7277 \\
& \mathrm{~T}=0.840 \mathrm{M}+3.11, \mathrm{R}^{2}=0.7579
\end{aligned}
$$

\section{Arithmetic and geometric mean diameter of date palm fruits}

Table 1 indicates the average diameter calculated by the arithmetic mean and geometric mean of fresh date palm fruits. As moisture content increases the average diameter of fruit also increases. The arithmetic and geometric mean diameter of fresh date palm fruits measured at two moisture contents of 69.50 percent and 61.56 percent (w.b.) were found as $25.26 \mathrm{~mm}, 25.03$ $\mathrm{mm}$ and $24.60 \mathrm{~mm}, 24.41 \mathrm{~mm}$ respectively. The results obtained for the arithmetic and geometric mean diameter of date palm fruits were similar to the findings reported by Aviara et al., (2013), Hobani and Ahmed (2001), Jahromi et al., (2007) and Davies (2016). The arithmetic mean diameter and geometric mean diameter are important in designing of separating, harvesting, sizing and grinding machine. The relationships between the arithmetic mean diameter and geometric mean diameter and moisture content can be expressed using the regression equation as:

$\mathrm{D}_{\mathrm{a}}=0.8255 \mathrm{M}+4.185, \mathrm{R}^{2}=0.7268 \ldots$ (iv)
$\mathrm{D}_{\mathrm{g}}=0.8274 \mathrm{M}+4.056, \mathrm{R}^{2}=0.7496 \ldots(\mathrm{v})$

\section{Sphericity}

The value of sphericity for two different moisture content varied as 0.734 and 0.737(Table 1). This parameter plays important role in designing of handling equipment of fruits. It indicates that dates fruit is oval to cylindrical in shape. On the contrary, the date palm fruits could be as cylindrical considering the close value of breadth and thickness. However the exact shape of the date palm fruit can be described as oval to cylindrical with thickest portion at both end. The shape of the dates fruit in this study was found similar to the findings obtained by Hobani and Ahmed (2003), Jahromi et al., (2007) and Davies (2016). The 
relationship between sphericity and moisture content of date fruit can be represented by following equation as:

$$
\varnothing=0.8844 \mathrm{M}+0.0914, \mathrm{R}^{2}=0.7899 \ldots(\mathrm{vi})
$$

\section{Surface area}

The surface area calculated at the surface area of fresh date palm fruits has been presented in Table 1 . The surface area of the date palm fruit increased from $1870.96 \mathrm{~mm}^{2}$ to 1900.20 $\mathrm{mm}^{2}$ as moisture content increased from $61.56 \%$ to $69.5 \%$ (w.b.). Similar trend have been reported by Hobani and Ahmed (2003), Jahromi et al., (2007) and Davies (2016).The relationship between surface area of date palm fruits and moisture content can be expressed by the following relationship as: $\mathrm{S}_{\mathrm{a}}=0.0 .988 \mathrm{M}-71314, \mathrm{R}^{2}=0.7297 \ldots$ (vii)

\section{One thousand fruit mass}

As seen in the Table 1, one thousand date palm fruits mass shows an increased from $8388 \mathrm{~g}$ to $8476 \mathrm{~g}$ when measured for two ascending moisture contents of $61.56 \%$ to $69.5 \%$ (w.b.). Average weight of a whole fruit, flesh and pit of date palm fruits recorded were equivalent to $8.48 \mathrm{~g} 7.24 \mathrm{~g}$ and $1.24 \mathrm{~g}$ respectively. The proportionate mass of flesh and pit found in whole dates fruit was calculated to be 85.37 percent and 14.63 percent respectively. The flesh and pit ratio was 5.84:1. Similar trend have been reported by Hobani and Ahmed (2003), Jahromi et al., (2007) and Davies (2016).The relationship between one thousand fruits weight and moisture content of the date palm fruits can be expressed by the following relationship as:

$$
\mathrm{M}_{1000}=0.0069 \mathrm{M}+7.31, \mathrm{R}^{2}=0.6755 \ldots \text { (viii) }
$$

\section{Bulk density}

The value of bulk density of the date palm fruits at different moisture contents were calculated and presented in Table 1. The bulk density varied as $491 \mathrm{~kg} / \mathrm{m}^{3}$ and $477 \mathrm{~kg} / \mathrm{m}^{3}$ which indicated a bulk density decreased with increase in the moisture content from 61.56 percent to 69.5 percent (w. b.). This parameter is important for storage study. Davies (2016) reported the value of bulk density as 512.91 $\mathrm{kg} / \mathrm{m}^{3}$. Similar results have been reported by Hobani and Ahmed (2003) and Jahromi et al., (2007). They also reported that the bulk density of the date palm fruit decreased as the moisture content increases. The relationship between bulk density and moisture content of the dates can be expressed by the following equation as:

$\mathrm{P}_{\mathrm{b}}=-1.1099 \mathrm{M}-15.57, \mathrm{R}^{2}=0.6023 \ldots$ (ix)

\section{True density}

The value of true density of the date palm fruits calculated at two different moisture contents were presented in Table 1 . The true density decreased from $576 \mathrm{~kg} / \mathrm{m}^{3}$ to 533 $\mathrm{kg} / \mathrm{m}^{3}$ when the moisture content increased from 61.56 to $69.5 \%$ (w. b.). Davies (2016) reported the true density of date palm fruits as $553.71 \mathrm{~kg} / \mathrm{m}^{3}$. Similar findings have been reported by Hobani and Ahmed (2003) and Jahromi et al., (2007). The relationship between True density and moisture content of the date palm fruits can be expressed by the following equation as:

$\mathrm{P}_{\mathrm{t}}=-00.794 \mathrm{M}+6.363, \mathrm{R}^{2}=0.6274 \ldots(\mathrm{x})$

\section{Porosity}

The value of porosity of the date palm fruits at two different moisture contents were calculated and are presented in Table 1 . The porosity varied by 10.56 percent and 14.75 percent under moisture content of 61.56 percent and 69.5 percent (w.b.) respectively. The porosity of date palm fruits is important because it shows the resistance of the fruits to 
air flow during drying process. This parameter is also vital for storage study. Davies (2016) reported 14.10 percent for the same parameter. The relationship between porosity and moisture content of the date palm fruits can be expressed by the following equation as:

$£=0.9905 \mathrm{M}-7.278, \mathrm{R}^{2}=0.343 \ldots(\mathrm{xi})$

Table.1 Physical properties of fresh date palm fruits

\begin{tabular}{|c|c|c|}
\hline \multirow[t]{2}{*}{ Physical property } & \multicolumn{2}{|c|}{ Moisture content (\%) (w.b.) } \\
\hline & 69.50 & 61.56 \\
\hline Length, mm & 33.65 & 33.12 \\
\hline Breadth, mm & 22.12 & 22.03 \\
\hline Thickness, mm & 20.02 & 19.95 \\
\hline Arithmetic mean, $\mathrm{mm}$ & 25.26 & 25.03 \\
\hline Geometric mean, mm & 24.60 & 24.41 \\
\hline Sphericity & 0.734 & 0.737 \\
\hline Surface Area, $\mathbf{m m}^{2}$ & 1900.20 & 1870.96 \\
\hline Bulk density, kg/m ${ }^{3}$. & 477.00 & 491.00 \\
\hline True density, kg/m³ & 533.00 & 576.00 \\
\hline Porosity, \% & 10.56 & 14.75 \\
\hline 1000 fruit mass, $\mathrm{g}$. & 8476 & 8388 \\
\hline Angle of repose, degree & 21.34 & 18.76 \\
\hline \multicolumn{3}{|c|}{ Coefficient of static friction } \\
\hline Wood & 0.34 & 0.31 \\
\hline steel & 0.32 & 0.27 \\
\hline Glass & 0.26 & 0.24 \\
\hline
\end{tabular}

\section{Angle of repose}

The values of the angle of repose corresponding to moisture contents are given in Table 1. The angle of repose increases $18.76^{\circ}$ to $21.34^{\circ}$ as moisture content increases from 61.56 percent to 69.5 percent.

Ndubisi et al., (2015) reported that the angle of repose of date palm fruit and kernel was found to be 19.82 and $34.94^{\circ}$ (digila), 18.07 and $33.36^{\circ}$ (krikri), 21.93 and $29.0^{\circ}$ (sukur) and 25.49 and $20.93^{\circ}$ (trigal). The relationship between angle of repose and moisture content of the date palm fruits can be expressed by the following equation as:

Tan $\not=0.8714 \mathrm{M}-0.205, \mathrm{R}^{2}=0.2484 \ldots(\mathrm{xii})$

\section{Coefficient of static friction}

The coefficient of static friction of date palm fruits was determined against three different structural surfaces i.e. wood, steel and glass. The results in Table 1 shows that the values of coefficient of static friction found for two moisture contents were 0.31 and 0.35 for wood, 0.30 and 0.33 for steel and 0.25 and 0.27 for glass respectively. Wood sheet showed highest static coefficient of friction attributed to greatest surface roughness with respect to steel and glass surfaces. Glass showed least coefficient of static friction. This parameter is important for designing pneumatic conveying systems, screw conveyors and hoppers. It is also used in the calculation of compressibility and flow 
behaviour of materials used for designing seed bins and other storage structures (Davis, 2016). Similar results were reported by Hobani and Ahmed (2001) and Jahromi et al., (2007). The relationship between coefficient of static friction and moisture content of the date palm fruits for wood, steel and glass can be expressed by the following equation as:

$\mu_{\mathrm{w}}=0.8856 \mathrm{M}+0.0089, \mathrm{R}^{2}=0.7143 \ldots$ (xiii)

$\mu_{\mathrm{s}}=0.8859 \mathrm{M}-0.0135, \mathrm{R}^{2}=0.6 \ldots$ (xiv)

$\mu_{\mathrm{g}}=0.8856 \mathrm{M}+0.0097, \mathrm{R}^{2}=0.4 \ldots(\mathrm{xv})$

In conclusion, the average length of the fresh Zahidi (Variety) date fruit $33.65 \mathrm{~mm}$; breadth 21.68 and thickness $20.56 \mathrm{~mm}$. It was found that the thickness and breadth were very close to each other while the length was higher due to its shape of the date fruits. The average value of the surface area of the date fruit was obtained $1886.32 \mathrm{~mm}^{2}$. The weight of one fruit of date was $8.48 \mathrm{~g}$. The weight of flesh date fruit was $7.24 \mathrm{~g}$ and weight of date pit was $1.24 \mathrm{~g}$. The percentage of flesh and pit were $85.37 \%$ and $14.63 \%$ respectively. The average value of bulk density was $460 \mathrm{~kg} / \mathrm{m}^{3}$. The average value of true density was 560 $\mathrm{kg} / \mathrm{m}^{3}$. The average value of porosity was $20.7 \%$. The angle of repose increase 15.23 $22.37^{\circ}$ as moisture content increases from 61.56 to $69.5 \%$. The average values of angle of repose of date fruit was $19.34^{\circ}$.The average value of coefficient of static friction were 0.33 (wood surfaces), 0.31 (steel surfaces) and 0.26 (glass surface) respectively.

\section{References}

Ali I. Hobani, AmarNishad M. Thottam, Khaled A.M. Ahmed,(2003).
"Development of a Neural Network Classifier for Date Fruit Varieties Using Some Physical Attributes", Res. Bult., No. (126), Agric. Res. Centre, King Saud Univ., pp. 5-18.

Davies, R. M. (2016) the study of the post harvest engineering properties date palm fruit and kernel for primary processing. Journal of Scientific Research in Engineering \& Technology Volume (1) Issue (1) Year (2016).

Keramat, Jahromi, M., A. Jafari, A.R. Keynani (2007). Some physical properties of date fruit ( $\mathrm{Cv}$. Lastit), Agril Engineering, International; VolIX, 202-209.

Khaled Selim, Mohamed Abdel-Bary, Osama Ismail (2012). Effect of irradiation and heat treatments on the quality characteristics of siwi date fruits. Agro Life Scientific Journal - Volume 1, 2012 CD-ROM ISSN 2285-5726

Mohsenin, N. N. (1980). Physical properties of plant and animal materials, Gordon and Breach Science publishers, New York.

Ndubisi A. Aviara, Mary E. Onaji, Abubakar A. Lawal. (2015). Moisture dependent physical properties of Detarium microcarpum seed. AgricEngInt: CIGR Journal, 17(4):311-326.

Pradhan, R.C., Naik S.N., Bhatnagar, N.and Vijay, V.K.(2009). Moisture dependent physical properties of jatropha fruits industrial crops and products. 29: 341-347.

\section{How to cite this article:}

Desai, N.N., V.M. Modi, G.K. Saxena, Ramesh Harajibhai Chaudhari, Manoj Kumar Jaipal, K.H. Gohil and Alok Gora. 2019. Physical Properties of Dates Fruits. Int.J.Curr.Microbiol.App.Sci. 8(04): 1243-1249. doi: https://doi.org/10.20546/ijcmas.2019.804.143 